\title{
Ocular Toxoplasmosis: Recent Aspects of Pathophysiology and Clinical Implications
}

\author{
Uwe Pleyer ${ }^{\mathrm{a}}$ Dirk Schlüter ${ }^{\mathrm{b}}$ Martin Mänz ${ }^{\mathrm{a}}$ \\ ${ }^{a}$ Eye Clinic, Charité - Universitätsmedizin Berlin, Berlin, and ${ }^{\mathrm{b}}$ Institute of Medical Microbiology, \\ Otto von Guericke University Magdeburg, Magdeburg, Germany
}

\section{Key Words}

Immunology · Ocular toxoplasmosis · Pathology .

Toxoplasma gondii $\cdot$ Uveitis

\begin{abstract}
Toxoplasma gondii is an extremely successful opportunistic parasite which infects approximately one third of the human population worldwide. The impact of this parasite on human health becomes particularly manifest in congenital damage with infection and subsequent inflammation of neuronal tissues including the retina. Although advances in our understanding could be achieved in ocular toxoplasmosis, large gaps still exist on factors influencing the epidemiology and pathophysiology of this potentially blinding disease. We are only at the beginning of understanding the complex biology of this parasite and its mechanisms of invasion, virulence and interaction with the host's immune response. Since it is a preventable cause of blindness, it is necessary to assess factors that have the potential to control this disease in the future. This mini review will focus on recent advances in postnatal acquired ocular infection and the factors that may influence its prevalence and functional outcome.
\end{abstract}

(c) 2014 S. Karger AG, Basel

\section{KARGER}

(C) 2014 S. Karger AG, Base

0030-3747/14/0523-0116\$39.50/0

E-Mail karger@karger.com

www.karger.com/ore

\section{Introduction}

The obligate intracellular protozoan parasite Toxoplasma gondii is an important opportunistic agent that infects all warm-blooded vertebrates including humans. Two major routes of infection exist. First, humans may become infected by oral ingestion of Toxoplasma oocysts, which are produced in the intestine of its specific host, the cat and other Felidae, and released by their feces into the environment. Second, infection occurs by oral uptake of Toxoplasma tissue cysts, which persist in skeletal muscles of intermediate hosts including pigs and sheep. Primary infection during pregnancy may result in fetal infection with fetal death, severe congenital malformation or, especially with infection at later stages of gestation, mild infection of neuronal tissue including the retina. However, more frequently, the pathogen is acquired postnatally, which also results in infection of neuronal tissues and, in most cases, takes a clinically asymptomatic course. It is considered the most frequent foodborne parasitic infection globally [1]. Importantly, ocular involvement is a major pathology following both routes of infection and may cause legal blindness. Worldwide ocular toxoplasmosis is considered the most frequent cause of infectious posterior uveitis. 


\section{Epidemiology}

Postnatally acquired ocular toxoplasmosis occurs in approximately 2 out of 100 seropositive individuals, suggesting that 1 in 400 persons across the world will have posterior uveitis due to T. gondii [1]. The large burden on health care systems as a result of ocular toxoplasmosis is illustrated e.g. by an estimated 250,000 patient visits to ophthalmologists in the USA alone [2].

Since ocular toxoplasmosis is a preventable cause of blindness, it is necessary to assess factors that have an impact on human infection. Based on current observations, the risk of acquiring an infection varies geographically and largely depends on control of the release and distribution of oocysts into the environment, the animal reservoir, meat consumption, personal habits and climatic conditions. In many countries, the prevalence of $T$. gondii cysts in livestock and the consumption of their contaminated meat are major factors influencing the rate of human infections.

The risk of infection by tissue cyst-containing meat is dependent on the animal species as well as the type of meat and its preparation and varies from country to country. In general, cysts survive in raw and undercooked but not in well-done prepared meat. With respect to the animal species, pigs and sheep are the dominant sources of T. gondii infections (fig. 1). As a consequence of industrialized meat production keeping livestock indoor, feeding sterilized food and keeping stables free of contact with rodents and cats, the prevalence of T. gondii in pigs is below $5 \%$ in Western countries [3]. Therefore, the risk of infection and seroconversion has declined in most countries in which less meat was consumed and hygiene standards were increased [4].

A significant decline in seroprevalence has been observed in Europe - e.g. in the Netherlands, where it dropped from $35.2 \%$ in 1996 to $18.5 \%$ in 2006 [5]. Of particular importance is the seroprevalence in childbearing women. In France, the proportion of seropositive pregnant women declined from $80 \%$ in the 1960 s to $44 \%$ in 2003 [6], indicating a significantly lower immune-mediated protection for the unborn child.

There is concern that the decline in exposure to T. gondii may be reversed in the future. Improved animal welfare and animal-friendly meat 'production' with outdoor containment are likely to increase the presence of T. gondii in meat products and will subsequently put consumers at higher risk of contracting toxoplasmosis [7].

Whereas in Western countries, a decrease in $T$. gondii seroprevalence was observed, the opposite may be true in regions with strong population growth and urbanization

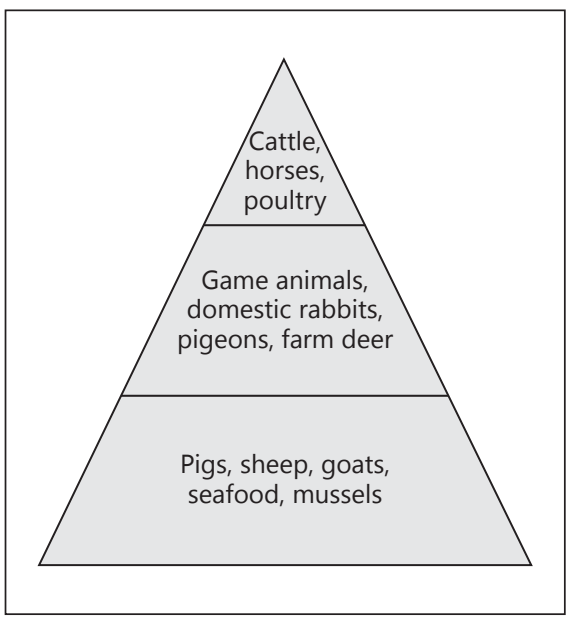

Fig. 1. Relative importance of food-related transmission of T. gondii to humans. Adapted from the Report of the WHO Consultation on Public Health Aspects of Toxoplasmosis and from several studies $[7-9,12-15]$.

trends, i.e. large parts of Asia [8]. The risk of foodborne infection seems much higher e.g. in China, where an average of $31 \%$ seroprevalence of $T$. gondii was found in slaughter pigs [9]. Large changes are expected for the future in the light of increased meat consumption in developing countries. A significantly higher risk of acquiring a T. gondii infection has also been observed in Russia, China and Indonesia [9-11].

Also, exposure to other reservoirs containing T. gondii, such as fresh water, may become an increasing source of infection. The quality of water is known as an important risk factor in human infection with oocysts. Contaminated water has repeatedly been a source of epidemics with ocular toxoplasmosis $[12,13]$. Drinking unfiltered surface water bears a high risk of infection especially in countries with humid weather conditions. Since global climate changes are predicted in coming years, this may have an impact on the T. gondii prevalence in humans [14]. Interestingly, also seawater and seafood such as mussels or oysters are frequently (45-100\%) contaminated with $T$. gondii oocysts and may account for a still underestimated source of human infections [15].

\section{Pathophysiology}

\section{How and Why Does the Eye Become Affected?}

It is probably not by chance that the three main immune-privileged areas of the body, the placenta, the brain 


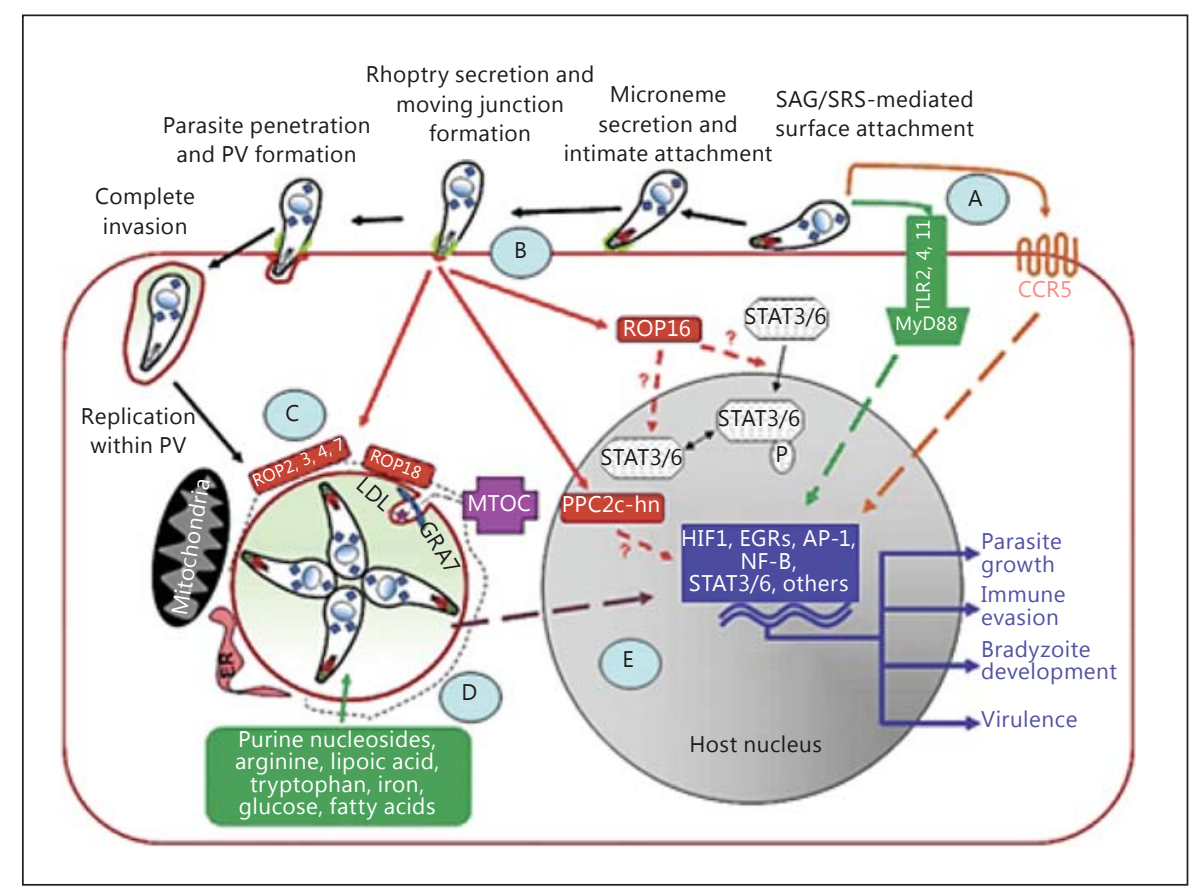

Fig. 2. T. gondii-host cell interactions. (A) Innate immune responses are initiated by TLR and CCR5 recognition of Toxoplasma-derived factors. (B) Parasite invasion is accomplished by the release of micronemal adhesins that interact with host surface factors. This is then followed by rhoptry secretion that results in the formation of the moving junction and in the release of parasite factors (e.g. ROP2 family members, ROP16, ROP18) that either interact with the parasitophorous vacuole (PV; ROP2 family and ROP18) or are transported to the host cytoplasm (ROP16) or nucleus. Some of these factors (ROP16 and ROP18) are polymorphic virulence factors. (C) Intracellular parasites reorganize host mitochondria and the endoplasmic reticulum (ER) as well as the host microtubule-organizing center (MTOC) and the cytoskeleton around the PV. Host microtubules associated with LDL-loaded cholesterol form membrane tubules that push into the PV and are wrapped with the dense granule protein GRA7. (D) Small soluble nutrients freely diffuse across the PV and then are taken up by the parasite, presumably by membrane transporters. (E) Host transcription is regulated either by the parasite directly activating host transcription factors or by the parasite triggering host signaling cascades that culminate in activating the host transcription factors. Changes in host gene expression can act to either promote parasite growth, immune evasion, virulence or bradyzoite development. Reprinted with permission from Blader and Saeij [19]. and the eye, are major targets of pathology in humans. The unique immunological milieu (e.g. high levels of TGF- $\beta$ ) may provide preconditions for a specific balance between parasite invasion and host resistance. Following primary infection of intestinal epithelial cells, T. gondii disseminates via the bloodstream throughout the host and has the ability to cross vascular barriers, e.g. the blood-brain barrier, and to form local cysts [16, 17]. Although free tachyzoites have recently been observed in human blood samples, it is unlikely that these parasites are able to infect ocular tissue directly. It is the current understanding that dendritic cells and macrophages serve as 'Trojan horses' to guide the parasite throughout the body into the target organs $[17,18]$.

Invasion of the host cell differs from other microorganisms and is mainly an active parasite-driven process, based on the interaction of several parasite-host surface ligands. Following attachment, unknown triggers activate calcium-dependent protein kinases, which in turn regulate motility and parasite invasion (fig. 2) [19]. In the host cell, the parasite protects itself from toxic host molecules in a parasitophorous vacuole. During invasion and intracellular infection, the host cell remains astoundingly passive, with little change of the actin cytoskeleton or protein phosphorylation. This finding is considered to be due to the manipulation of intracellular signaling by the parasite, which secretes immune modulators (e.g. ROP and GRA proteins) into the cytoplasm of the host cell. Notably, the parasite simultaneously provokes the production of proinflammatory IFN- $\gamma$ and IL-12, but at the same time $T$. gondii suppresses a strong Th1 immune response. This balanced immune response allows the immunologi- 
Fig. 3. Simplified schematic graph of parasite destruction and immune pathology during T. gondii infection. Whereas IL-12 and IL-18 induce Th1 differentiation, TGF- $\beta$, IL- 6 and IL-23 promote the expansion and differentiation of Th17 cells. The regulatory functions of IL-10, TGF- $\beta$ and IL-27 in supporting the immune responses are illustrated.

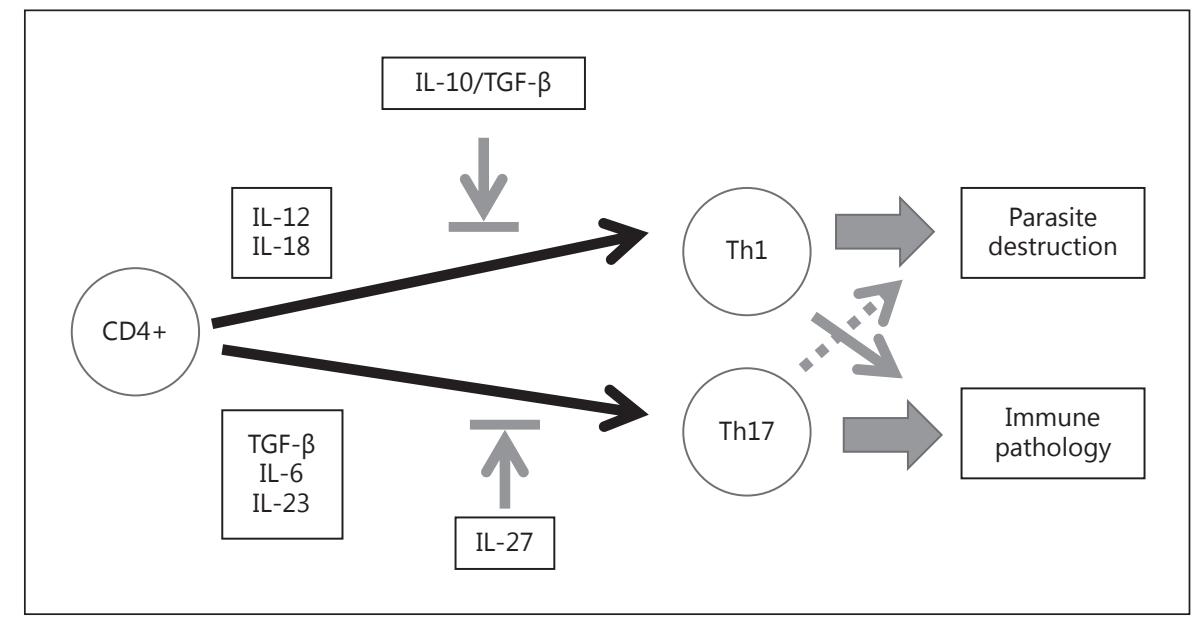

cal control of the parasite and, in parallel, prevents an immunopathology. As an important regulatory component, Th17 cells have been identified as key contributors to this balance of immune pathological response in the eye (fig. 3). Th17 cells are characterized by the production of IL-17 mediated by IL-23 from dendritic cells and probably may have both protective and proinflammatory effects. Different roles in infectious and inflammatory events are likely to be related to the local (cytokine) environment and the stage of the pathological process [2022].

Recent clinical and experimental studies indicate intraocular overexpression of IL-17A in active ocular toxoplasmosis. Interestingly, in one study, the production of this signature cytokine occurred early in the course of infection and was predominantly caused by resident retinal cells rather than infiltrating T cells [23]. Since IL-17A is a well-known inducer of proinflammatory responses and autoimmune diseases, this may have direct pathogenic and therapeutic implications. In contrast, however, IL-17 demonstrated strong neuroprotective properties by inhibiting intracellular calcium, maintenance of homeostasis and prevention from apoptosis in active uveitis [24]. The exact role of IL-17A in infectious diseases is therefore ambiguous, varying between antipathogenic activity and tissue destruction.

It is increasingly clear that parasite- as well as hostspecific factors are important determinants of whether an infection results in ocular manifestation. This is likely the key to answering the question why some individuals develop ocular disease, whereas others remain in an asymptomatic stage.

Ocular Toxoplasmosis

\section{Parasite-Related Factors: Do T. gondii Strains Influence Clinical Features?}

There is an ongoing discussion whether the infection and the severity of ocular toxoplasmosis are influenced by genotypic differences between infecting parasites. T. gondii exists in three main clonal lineages (strains I, II and III), with type I strains being highly virulent and often lethal in mouse models of infection. Type II and III strains are only moderately virulent under identical experimental conditions [25]. These differences observed in animals have a genetic basis and are linked to certain gene loci coding for rhoptry proteins (ROP18, ROP5 and ROP16) $[25,26]$.

Also in humans, type I strains have been reported to cause severe postnatally acquired ocular toxoplasmosis in Brazil [27]. Further evidence for severe fulminant retinitis caused by $T$. gondii type I strains derives from vitreous humor samples of patients who underwent vitrectomy [28]. Based on these studies, two subgroups of patients could be distinguished. All patients affected by type I strains were otherwise healthy and immune competent, whereas patients infected with type II and III strains were immune deficient [28]. From these observations, it might be concluded that in immune-competent patients, the genotype of parasite dominates the clinical course of ocular toxoplasmosis, whereas in immune-deficient patients, host factors are more important and severe ocular toxoplasmosis can be caused by any parasite type.

However, sexual recombination allows much larger parasite diversity, and currently more than 130 'atypical' genotypes have been characterized [29]. Differences in the virulence of these strains have again been shown for 
mice [30], but the role in humans is more difficult to establish. Unfortunately, it is difficult to detect these differences in patients, since intraocular parasite DNA in clinical specimens from patients with ocular toxoplasmosis is often limited and frequently not detected. To partly overcome this problem, ELISA methods have been developed that allow serotyping of parasites based on patients' antibody repertoire directed against certain allelic peptide motifs [31]. This serotyping approach has the advantage that it can be extended to a healthy seroconverted population and no parasite isolation is needed. By serotyping, a dominance of type II-specific antibody response was observed in positive but clinically asymptomatic Europeans [32-35]. Interestingly, using this technique, an 'atypical' nonreactive serotype was significantly more frequently detected in sera of patients with ocular toxoplasmosis than in seroconverted individuals without ocular involvement ( $\mathrm{p}<0.0001$ ). Among ocular toxoplasmosis patients, those with this serotype experienced more frequent recurrences $(p=0.037)$ [36]. In line with these findings are results from a cohort of 193 patients with congenital toxoplasmosis in North America. Using the same detection method, the nonreactive serotype was associated with prematurity $(\mathrm{p}=0.03)$ and severe disease at birth $(\mathrm{p}<$ 0.01) [37].

\section{Host Genetic Factors: Do They Play a Role in the Susceptibility to and Severity of Ocular Toxoplasmosis?}

Whether susceptibility to ocular toxoplasmosis differs between individuals remains an important question. At least five genes at the MHC locus have been associated with protection and resistance to otherwise lethal T. gondii infection in experimental rodent models [38]. With respect to humans, early studies have shown a significant association of the HLA-DQ3 genotype with congenital $T$. gondii encephalitis and hydrocephalus [39] but not with ocular involvement. However, more recent observations mainly focusing on congenital toxoplasmosis imply that a number of gene polymorphisms are linked to susceptibility.

Both encephalitis and retinitis could be linked to the ABCA4-encoding genes that are selectively expressed in the choroid plexus throughout the development of the eye and brain and are closely related to hereditary retina dystrophies. This may suggest a possible role for ABCA4 in determining the simultaneous pathology in the brain and eye, as often seen in congenital toxoplasmosis [40, 41].
In addition, Toll-like receptors (TLR) are important transmembrane proteins that recognize microbial components and orchestrate an early immune defense, leading to the production of proinflammatory cytokines. Supported by a small family-based study in children with congenital ocular toxoplasmosis, a significant association between gene polymorphisms of TLR (TLR2, TLR5 and TLR9) was reported [42].

Probably not unexpected, host cytokine gene polymorphisms have been a focus of interest in toxoplasmic retinitis. Cytokines, in particular IFN- $\gamma$ and TNF- $\alpha$, play an essential role in resistance to $T$. gondii infections (fig. 2). These cytokines activate macrophages, a major first defense line. Polymorphisms in genes encoding various cytokines have been shown to be connected with susceptibility to parasitic diseases. Indeed, individuals homozygous for the A allele (+874T/A) of the IFN $-\gamma$ gene had a higher risk of ocular toxoplasmosis if they possessed the A/A genotype as compared to a negative control group [43]. In addition, experimental data have demonstrated a relevant role for the anti-inflammatory cytokine IL-10 in modulating acute ocular toxoplasmosis. An IL10 gene polymorphism (IL-10 -1082 A allele, AA+AG genotypes) could be associated with the occurrence of ocular toxoplasmosis. More recently, a study conducted by Cordeiro et al. [44] similarly identified and associated an IL-6 polymorphism $(-174 \mathrm{G} / \mathrm{C})$ with the occurrence but not recurrence of ocular toxoplasmosis in Brazilian patients.

An interesting finding bridges autoinflammatory and immunoregulatory mechanisms in patients with toxoplasmic retinochoroiditis. In children with congenital ocular toxoplasmosis, an association with polymorphisms in the NOD2 gene, an intracellular pattern recognition receptor, could be detected [45]. Of note, the results further suggested that NOD2 influences the production of IL-17A by CD4+ T lymphocytes and likely contributed to the development of ocular toxoplasmosis.

Taken together, a variety of gene polymorphisms are involved in (ocular) toxoplasmosis and may relate to an individual risk profile for a given patient. This may hopefully also open future avenues for studying host-parasite interaction and allow more specific preventive/therapeutic modulation.

\section{Other Factors}

A variety of other factors may influence the susceptibility to and severity of ocular toxoplasmosis. 


\section{Patients' Age}

The role of patients' age has been debated for decades. It is commonly observed that ocular toxoplasmosis is more prevalent and active in younger individuals and becomes initially manifest between the ages of 25 and 31 years. This may suggest a higher risk at younger age; however, given the natural, steadily increasing seroconversion over decades, this distribution may not be true. Instead, a critical evaluation identifies age at the extreme ends as a risk for the clinical manifestation of ocular toxoplasmosis. Not only patients with congenitally acquired infection but also those at older age seem to be at higher risk for the clinical manifestation of ocular toxoplasmosis. Patients whose ocular toxoplasmosis was first diagnosed and presented recent seroconversion were substantially older (mean age: 50.6 years) than patients with a first manifestation of ocular toxoplasmosis with serologic evidence of an infection some time ago (mean age: 29.9 years) [46].

Interestingly, the more advanced age of patients at first manifestation had an impact on the risk of recurrences as well. The relative risk for individuals aged $\geq 40$ years was significantly increased $(\mathrm{p}<0.03)$ and presumably related to the waning immune defense in the aging host [47]. The overall recurrence rate in Europe is up to $80 \%$ within 5 years, with the highest rate during the first year following an active episode of retinochoroiditis [46-49]. It has been postulated that recurrences are associated with the proliferation of organisms that emerge from retinal tissue cysts. Over time, the viability of tissue cysts decreases and they eventually die, reducing the pool of organisms and risk of reactivation. Other factors that have been considered to influence recurrences are changes in tissue cysts with reduced release of parasites or antigens, trauma, endocrine fluctuations and transient humoral or cellular immunoreactivity $[50,51]$. However, none of these putative factors could be substantiated. Most notably, no association between recurrence and treatment, congenital infections versus postnatally acquired infections, primary lesions versus recurrent lesions and the size of lesions or antibody levels could be established (for a review, see Mänz et al. [52]).

\section{Patients' Immune Status: Disease in}

\section{Immunocompromised Individuals}

Given the eminent role of the host immune system in ocular toxoplasmosis, an impact on the disease course can be expected in immunocompromised, e.g. HIV coinfected, individuals. Whether AIDS patients per se are at higher risk of primary acquired ocular toxoplasmosis is not clearly documented. Before the introduction of highly ac-

tive antiretroviral treatment, and even today without adequate treatment, toxoplasmic encephalitis remains an initial AIDS-defining illness in up to $33 \%$ of all patients [53]. It remains an important cause of neurological disorders, leading to severe pathology including lethal consequence [54]. Also ocular involvement is far more severe, even when compared to other opportunistic infections of the retina in AIDS patients, e.g. cytomegalovirus retinitis. The essential role of the host immune response is underlined by the fact that patients are at particular risk when CD4+ T cell numbers are reduced below 200 cells $/ \mathrm{mm}^{3}$ and, therefore, subsequent monitoring is advised [55]. Often these individuals demonstrate an atypical fulminant clinical course of ocular toxoplasmosis and provide a great diagnostic challenge. Similar problems and atypical clinical presentations of ocular toxoplasmosis can be seen in patients receiving immunosuppressive drug therapy, e.g. following organ or bone marrow transplantation [56]. The prevalence of ocular toxoplasmosis in this population at risk is not known, but careful monitoring of infections in this increasing population is advised [57].

\section{Conclusions}

Since a reliable animal model of ocular toxoplasmosis is still missing and will be hard to establish, the research focus on ocular toxoplasmosis is likely to remain clinical. Many questions concerning not only the epidemiology, impact of parasite strains and role of protective and immunopathological immune response but also therapeutic approaches are still unresolved. Close cooperation of ophthalmologists with parasitologists, microbiologists and immunologists are mandatory.

\section{Acknowledgments}

This review was supported in part by the German Federal Ministry of Education and Research (BMBF) through the Toxonet 02 research collaboration.

References

Ophthalmic Res 2014;52:116-123 DOI: $10.1159 / 000363141$
1 Holland GN: Ocular toxoplasmosis: a global reassessment. Part I. Epidemiology and course of disease. Am J Ophthalmol 2003;136: 973-988.

2 Kirby T: Calls for more detailed studies on toxoplasmosis. Lancet Infect Dis 2012;12: 912-913.

3 Dubey JP, Jones JL: Toxoplasma gondii infection in humans and animals in the United States. Int J Parasitol 2008;38:1257-1278. 
-4 Kijlstra A, Jongert E: Toxoplasma-safe meat: close to reality? Trends Parasitol 2009;25:1822.

5 Hofhuis A, van Pelt W, van Duynhoven YT, Nijhuis CD, Mollema L, van der Klis FR, Havelaar AH, Kortbeek LM: Decreased prevalence and age-specific risk factors for Toxoplasma gondii IgG antibodies in the Netherlands between 1995/1996 and 2006/2007. Epidemiol Infect 2011;139:530-538.

-6 Nogareda F, Le Strat Y, Villena I, De Valk H, Goulet V: Incidence and prevalence of Toxoplasma gondii infection in women in France, 1980-2020: model-based estimation. Epidemiol Infect 2014;142:1661-1670.

7 Tenter AM, Heckeroth AR, Weiss LM: Toxoplasma gondii: from animals to humans. Int $\mathrm{J}$ Parasitol 2000;30:1217-1258.

-8 Zhou DH, Zhao FR, Lu P, Xia HY, Xu MJ, Yuan LG, Yan C, Huang SY, Li SJ, Zhu XQ: Seroprevalence of Toxoplasma gondii infection in dairy cattle in southern China. Parasit Vectors 2012;5:48.

-9 Wu D, Lv R, Sun X, Shu F, Zhou Z, Nie K, Duan G, Zou F: Seroprevalence of Toxoplasma gondii antibodies from slaughter pigs in Chongqing, China. Trop Anim Health Prod 2012;44:685-687.

10 Singh S, Khang TF, Andiappan H, Nissapatorn V, Subrayan V: An age-adjusted seroprevalence study of Toxoplasma antibody in a Malaysian ophthalmology unit. Trans R Soc Trop Med Hyg 2012;106:322-326.

-11 Dolgikh TI, Zaparii NS, Kadtsyna TV, Kalitin AV: Epidemiological and clinicoimmunological monitoring of toxoplasmosis in the Omsk region (in Russian). Med Parazitol (Mosk) 2008;1:19-22.

12 Bowie WR, King AS, Werker DH, Isaac-Renton JL, Bell A, Eng SB, Marion SA: Outbreak of toxoplasmosis associated with municipal drinking water. The BC Toxoplasma Investigation Team. Lancet 1997;350:173-177.

-13 de Moura L, Bahia-Oliveira LM, Wada MY, Jones JL, Tuboi SH, Carmo EH, Ramalho WM, Camargo NJ, Trevisan R, Graca RM, da Silva AJ, Moura I, Dubey JP, Garrett DO: Waterborne toxoplasmosis, Brazil, from field to gene. Emerg Infect Dis 2006;12:326-329.

14 Meerburg BG, Kijlstra A: Changing climatechanging pathogens: Toxoplasma gondii in North-Western Europe. Parasitol Res 2009; 105:17-24.

15 Jones JL, Dubey JP: Waterborne toxoplasmosis: recent developments. Exp Parasitol 2010 124:10-25.

16 Feustel SM, Meissner M, Liesenfeld O: Toxoplasma gondii and the blood-brain barrier. Virulence 2012;3:182-192.

17 Lachenmaier SM, Deli MA, Meissner M, Liesenfeld O: Intracellular transport of Toxoplasma gondii through the blood-brain barrier. J Neuroimmunol 2011;232:119-130.
8 Courret N, Darche S, Sonigo P, Milon G, Buzoni-Gatel D, Tardieux I: CD11c- and CD11b-expressing mouse leukocytes transport single Toxoplasma gondii tachyzoites to the brain. Blood 2006;107:309-316.

19 Blader IJ, Saeij JP: Communication between Toxoplasma gondii and its host: impact on parasite growth, development, immune evasion, and virulence. APMIS 2009;117:458476.

20 Sauer A, Rochet E, Lahmar I, Brunet J, Sabou M, Bourcier T, Candolfi E, Pfaff AW: The local immune response to intraocular Toxoplasma re-challenge: less pathology and better parasite control through Treg/Th1/Th2 induction. Int J Parasitol 2013;43:721-728.

21 Guiton R, Vasseur V, Charron S, Arias MT, Van Langendonck N, Buzoni-Gatel D, Ryffel B, Dimier-Poisson I: Interleukin 17 receptor signaling is deleterious during Toxoplasma gondii infection in susceptible BL6 mice. J Infect Dis 2010;202:427-435.

- 22 O'Connor W Jr, Kamanaka M, Booth CJ, Town T, Nakae S, Iwakura Y, Kolls JK, Flavell RA: A protective function for interleukin 17A in $\mathrm{T}$ cell-mediated intestinal inflammation. Nat Immunol 2009;10:603-609.

-23 Sauer A, Pfaff AW, Villard O, Creuzot-Garcher C, Dalle F, Chiquet C, Pelloux H, SpeegSchatz C, Gaucher D, Prevost G, Bourcier T, Candolfi E: Interleukin $17 \mathrm{~A}$ as an effective target for anti-inflammatory and antiparasitic treatment of toxoplasmic uveitis. J Infect Dis 2012;206:1319-1329.

24 Hu M, Zheng Q, Jia X, Li Y, Dong Y, Wang C, Lin Q, Zhang F, Zhao R, Xu H, Zhou J, Yuan $\mathrm{H}$, Zhang W, Ren H: Neuroprotection effect of interleukin (IL)-17 secreted by reactive astrocytes is emerged from a high-level IL17-containing environment during acute neuroinflammation. Clin Exp Immunol 2014; 175:268-284.

25 Sibley LD, Boothroyd JC: Virulent strains of Toxoplasma gondii comprise a single clonal lineage. Nature 1992;359:82-85.

26 Dubremetz JF, Lebrun M: Virulence factors of Toxoplasma gondii. Microbes Infect 2012;14: 1403-1410.

27 Vallochi AL, Muccioli C, Martins MC, Silveira C, Belfort R Jr, Rizzo LV: The genotype of Toxoplasma gondii strains causing ocular toxoplasmosis in humans in Brazil. Am J Ophthalmol 2005;139:350-351.

28 Grigg ME, Ganatra J, Boothroyd JC, Margolis TP: Unusual abundance of atypical strains associated with human ocular toxoplasmosis. J Infect Dis 2001;184:633-639.

29 Su C, Khan A, Zhou P, Majumdar D, Ajzenberg D, Darde ML, Zhu XQ, Ajioka JW, Rosenthal BM, Dubey JP, Sibley LD: Globally diverse Toxoplasma gondii isolates comprise six major clades originating from a small number of distinct ancestral lineages. Proc Natl Acad Sci USA 2012;109:5844-5849.
30 Herrmann DC, Barwald A, Maksimov A, Pantchev N, Vrhovec MG, Conraths FJ, Schares G: Toxoplasma gondii sexual cross in a single naturally infected feline host: generation of highly mouse-virulent and avirulent clones, genotypically different from clonal types I, II and III. Vet Res 2012;43:39.

- 31 Kong JT, Grigg ME, Uyetake L, Parmley S, Boothroyd JC: Serotyping of Toxoplasma gondii infections in humans using synthetic peptides. J Infect Dis 2003;187:1484-1495.

32 Peyron F, Lobry JR, Musset K, Ferrandiz J, Gomez-Marin JE, Petersen E, Meroni V, Rausher B, Mercier C, Picot S, Cesbron-Delauw MF: Serotyping of Toxoplasma gondii in chronically infected pregnant women: predominance of type II in Europe and types I and III in Colombia (South America). Microbes Infect 2006;8:2333-2340.

-33 Sousa S, Ajzenberg D, Vilanova M, Costa J, Darde ML: Use of GRA6-derived synthetic polymorphic peptides in an immunoenzymatic assay to serotype Toxoplasma gondii in human serum samples collected from three continents. Clin Vaccine Immunol 2008;15: 1380-1386.

-34 Morisset S, Peyron F, Lobry JR, Garweg J, Ferrandiz J, Musset K, Gomez-Marin JE, de la Torre A, Demar M, Carme B, Mercier C, Garin JF, Cesbron-Delauw MF: Serotyping of Toxoplasma gondii: striking homogeneous pattern between symptomatic and asymptomatic infections within Europe and South America. Microbes Infect 2008;10:742-747.

35 Maksimov P, Zerweck J, Maksimov A, Hotop A, Gross U, Pleyer U, Spekker K, Daubener W, Werdermann S, Niederstrasser O, Petri E, Mertens M, Ulrich RG, Conraths FJ, Schares G: Peptide microarray analysis of in silicopredicted epitopes for serological diagnosis of Toxoplasma gondii infection in humans. Clin Vaccine Immunol 2012;19:865-874.

- 36 Shobab L, Pleyer U, Johnsen J, Metzner M, James ER, Torun N, Fay MP, Liesenfeld O, Grigg ME: Toxoplasma serotype is associated with development of ocular toxoplasmosis. J Infect Dis 2013;208:1520-1528.

- 37 McLeod R, Boyer KM, Lee D, Mui E, Wroblewski K, Karrison T, Noble AG, Withers S, Swisher CN, Heydemann PT, Sautter M, Babiarz J, Rabiah P, Meier P, Grigg ME: Prematurity and severity are associated with Toxoplasma gondii alleles (NCCCTS, 1981-2009). Clin Infect Dis 2012;54:1595-1605.

38 McLeod R, Brown C, Mack D: Immunogenetics influence outcome of Toxoplasma gondit infection. Res Immunol 1993;144:61-65.

39 Mack DG, Johnson JJ, Roberts F, Roberts CW, Estes RG, David C, Grumet FC, McLeod R: HLA-class II genes modify outcome of Toxoplasma gondii infection. Int J Parasitol 1999; 29:1351-1358 
40 Bhongsatiern J, Ohtsuki S, Tachikawa M, Hori S, Terasaki T: Retinal-specific ATPbinding cassette transporter (ABCR/ABCA4) is expressed at the choroid plexus in rat brain. J Neurochem 2005;92:1277-1280.

41 Jamieson SE, de Roubaix LA, Cortina-Borja $M$, et al: Genetic and epigenetic factors at COL2A1 and ABCA4 influence clinical outcome in congenital toxoplasmosis. PLoS One 2008;3:e2285.

42 Peixoto-Rangel AL, Miller EN, Castellucci L, Jamieson SE, Peixe RG, Elias Lde S, CorreaOliveira R, Bahia-Oliveira LM, Blackwell JM: Candidate gene analysis of ocular toxoplasmosis in Brazil: evidence for a role for toll-like receptor 9 (TLR9). Mem Inst Oswaldo Cruz 2009;104:1187-1190.

-43 Albuquerque MC, Aleixo AL, Benchimol EI, Leandro AC, das Neves LB, Vicente RT, Bonecini-Almeida Mda G, Amendoeira MR The IFN $-\gamma+874 \mathrm{~T} / \mathrm{A}$ gene polymorphism is associated with retinochoroiditis toxoplasmosis susceptibility. Mem Inst Oswaldo Cruz 2009;104:451-455.

44 Cordeiro CA, Moreira PR, Bessa TF, Costa GC, Dutra WO, Campos WR, Orefice F, Young LH, Teixeira AL: Interleukin-6 gene polymorphism $(-174 \mathrm{G} / \mathrm{C})$ is associated with toxoplasmic retinochoroiditis. Acta Ophthalmol 2013;91:e311-e314.
45 Shaw MH, Reimer T, Sanchez-Valdepenas C, Warner N, Kim YG, Fresno M, Nunez G: T cell-intrinsic role of Nod2 in promoting type 1 immunity to Toxoplasma gondii. Nat Immunol 2009;10:1267-1274.

46 Bosch-Driessen LE, Berendschot TT, Ongkosuwito JV, Rothova A: Ocular toxoplasmosis: clinical features and prognosis of 154 patients. Ophthalmology 2002;109:869-878.

47 Holland GN, Crespi CM, ten Dam-van Loon $\mathrm{N}$, Charonis AC, Yu F, Bosch-Driessen LH, Rothova A: Analysis of recurrence patterns associated with toxoplasmic retinochoroiditis. Am J Ophthalmol 2008;145:1007-1013.

48 de-la-Torre A, Rios-Cadavid AC, CardozoGarcia CM, Gomez-Marin JE: Frequency and factors associated with recurrences of ocular toxoplasmosis in a referral centre in Colombia. Br J Ophthalmol 2009;93:1001-1004.

49 Garweg JG, Scherrer JN, Halberstadt M: Recurrence characteristics in European patients with ocular toxoplasmosis. Br J Ophthalmol 2008;92:1253-1256.

50 Garweg JG, Scherrer J, Wallon M, Kodjikian L, Peyron F: Reactivation of ocular toxoplasmosis during pregnancy. BJOG 2005;112: 241-242.

51 O'Connor GR: Factors related to the initiation and recurrence of uveitis. XL Edward Jackson memorial lecture. Am J Ophthalmol 1983;96:577-599.
52 Mänz M, Schlüter D, Liesenfeld O, Schares G, Gross U, Pleyer U: Ocular toxoplasmosis past, present and new aspects of an old disease. Prog Retin Eye Res 2014;39:77-106.

-53 Silva AC, Rodrigues BS, Micheletti AM, Tostes S Jr, Meneses AC, Silva-Vergara ML, Adad SJ: Neuropathology of AIDS: an autopsy review of 284 cases from Brazil comparing the findings pre- and post-HAART (highly active antiretroviral therapy) and pre- and postmortem correlation. AIDS Res Treat 2012;2012:186850.

54 Weiss LM, Dubey JP: Toxoplasmosis: a history of clinical observations. Int J Parasitol 2009;39:895-901.

55 Thoden J, Potthoff A, Bogner JR, et al: Therapy and prophylaxis of opportunistic infections in HIV-infected patients: a guideline by the German and Austrian AIDS societies (DAIG/ÖAG) (AWMF 055/066). Infection 2013;41(suppl 2):S91-S115.

56 Chung H, Kim JG, Choi SH, Lee SY, Yoon $\mathrm{YH}$ : Bilateral toxoplasma retinochoroiditis simulating cytomegalovirus retinitis in an allogeneic bone marrow transplant patient. Korean J Ophthalmol 2008;22:197-200.

-57 Edvinsson B, Lundquist J, Ljungman P, Ringden O, Evengard B: A prospective study of diagnosis of Toxoplasma gondii infection after bone marrow transplantation. APMIS 2008; 116:345-351. 